\title{
Zeolitic imidazolate frameworks as latent thermal initiators in the curing of epoxy resin
}

Osamu Shimomura*, Hiroshi Furuya, Daiki Fukumoto, Atsushi Ohtaka, and Ryôki Nomura Department of Applied Chemistry, Osaka Institute of Technology

5-16-1 Omiya, Ashahi-ku, Osaka 535-8585, Japan 
Supporting Information

\section{Table of contents}

1. Materials

2. Preparation of ZIFs

2.1 Preparation of ZIF-8.

2.2 Preparation of ZIF-14.

2.3 Preparation of ZIF-7.

2.4 Preparation of ZIF-11.

Figure S1. XRD pattern of ZIF-8.

Figure S2. SEM image of ZIF-8.

Figure S3. XRD pattern of ZIF-14.

Figure S4. SEM image of ZIF-14.

Figure S5. XRD pattern of ZIF-7.

Figure S6. SEM image of ZIF-7.

Figure S7. XRD pattern of ZIF-11.

Figure S8. SEM image of ZIF-11. 


\section{Materials}

$\mathrm{Zn}\left(\mathrm{NO}_{3}\right) \cdot 6 \mathrm{H}_{2} \mathrm{O}, \mathrm{Zn}(\mathrm{OAc})_{2} \cdot 2 \mathrm{H}_{2} \mathrm{O}$, and 1-octanol were purchased from Fujifilm Wako Pure

Chemical Co. Ltd. (Osaka, Japan). Benzimidazole, 2-methylimidazole, and 2-ethylimidazole were purchased from Tokyo Chemical Industries, Co., Ltd. (Tokyo, Japan). Ammonia solution (28 -30\%) was purchased from Kanto Chemical Co., Inc. (Tokyo, Japan). Solvents and other chemicals were used without further purification.

\section{Preparation of ZIFs}

Zeolitic imidazolate frameworks of ZIF- $8,{ }^{1} \mathrm{ZIF}-14,{ }^{2} \mathrm{ZIF}-7,{ }^{3}$ and ZIF- $11^{4}$ were prepared by reported methods.

2.1 Preparation of ZIF-8. The methanol (500 mL) solution of $\mathrm{Zn}\left(\mathrm{NO}_{3}\right) \cdot 6 \mathrm{H}_{2} \mathrm{O}(14.88 \mathrm{~g}, 50.0$

mmol) and methanol (500 mL) solution of 2-methylimidazole (16.42 g, $200 \mathrm{mmol})$ was mixed and allowed to stand for $48 \mathrm{~h}$ at ambient temperature. The obtained product was recovered by the centrifugation $(9500 \mathrm{rpm}, 5 \mathrm{~min})$ and washed with methanol for 3 times. The washed residue was dried under vacuum to obtain $3.55 \mathrm{~g}$ ( $31 \%$ yield). 


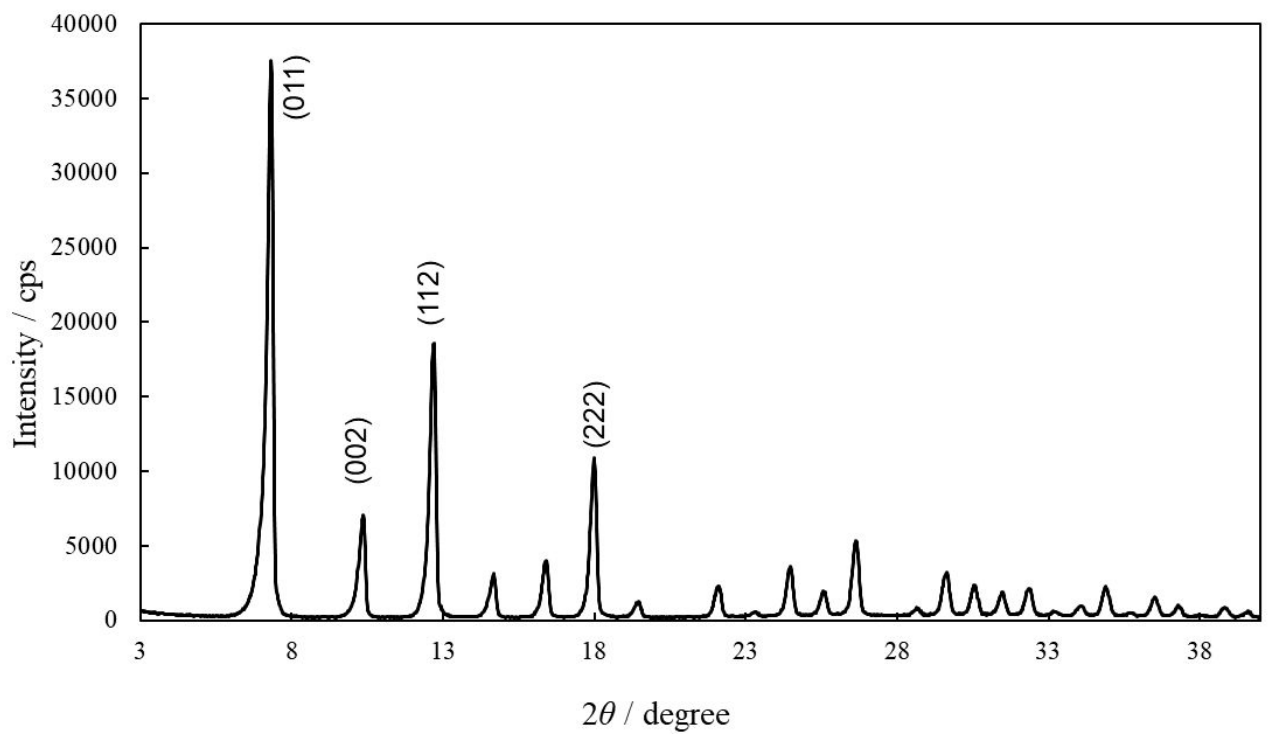

Figure S1. XRD pattern of ZIF-8.

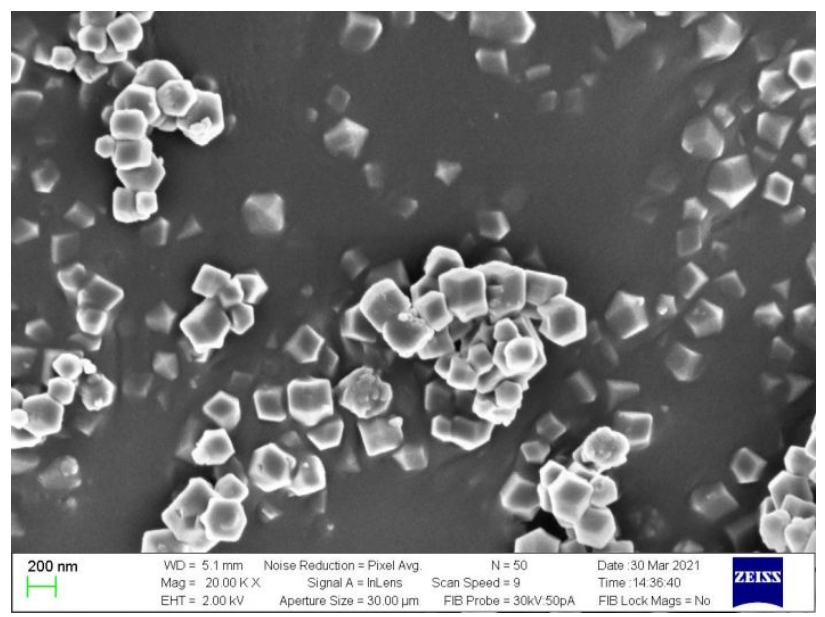

Figure S2. SEM image of ZIF-8. 
2.2 Preparation of ZIF-14. The 1-octanol (50 mL) solution of $\mathrm{Zn}\left(\mathrm{NO}_{3}\right) \cdot 6 \mathrm{H}_{2} \mathrm{O}(1.49 \mathrm{~g}, 5.0$

mmol) and $\mathrm{H}_{2} \mathrm{O}(50 \mathrm{~mL})$ solution of 2-ethylimidazole (1.92 g, $\left.20.0 \mathrm{mmol}\right)$ was stirring at ambient temperature for $2.5 \mathrm{~h}$. The obtained product was recovered by the centrifugation (9500 rpm, 5min) and washed with methanol for 3 times. The washed residue was dried at 60 ${ }^{\circ} \mathrm{C}$ under vacuum to obtain $0.61 \mathrm{~g}(47 \%$ yield $)$.

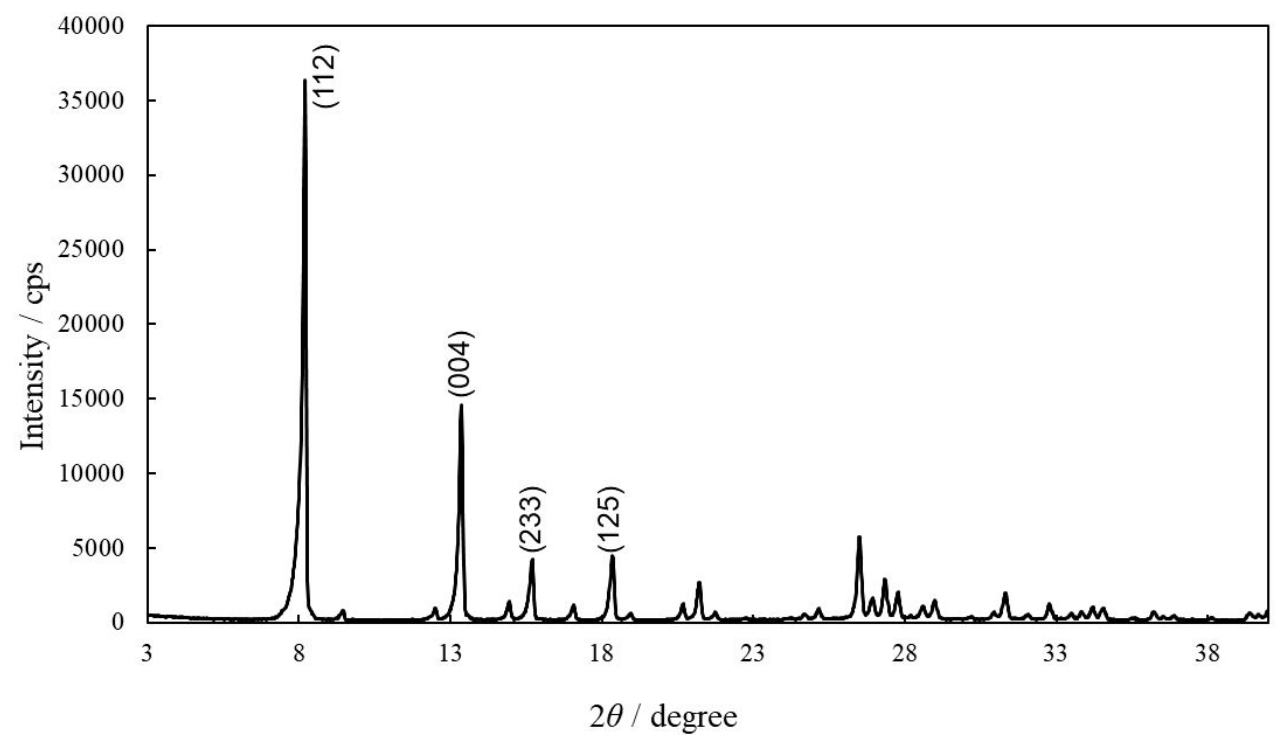

Figure S3. XRD pattern of ZIF-14 


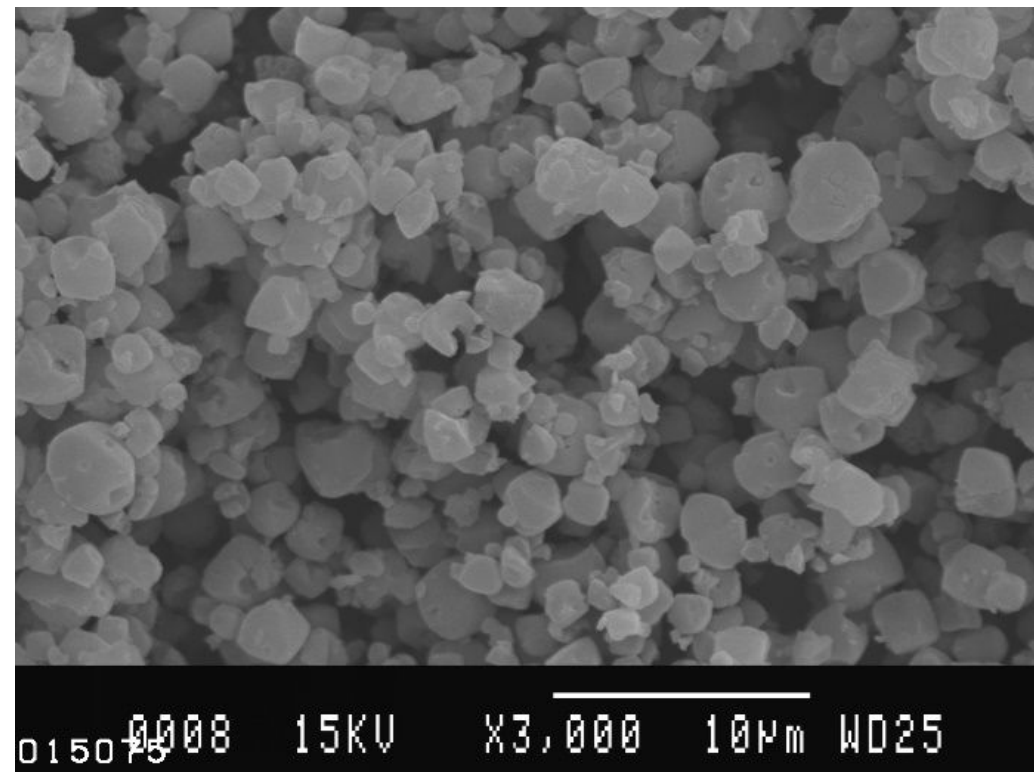

Figure S4. SEM image of ZIF-14.

2.3 Preparation of ZIF-7. The DMF (100 mL) solution of $\mathrm{Zn}\left(\mathrm{NO}_{3}\right) \cdot 6 \mathrm{H}_{2} \mathrm{O}(3.00 \mathrm{~g}, 10.1$ mmol) benzimidazole $(10.0 \mathrm{~g}, 84.6 \mathrm{mmol})$ was stirring at ambient temperature for $2.5 \mathrm{~h}$. The obtained product was recovered by the centrifugation $(9500 \mathrm{rpm}, 5 \mathrm{~min})$ and washed with methanol for 3 times. The washed residue was dried at $100{ }^{\circ} \mathrm{C}$ under vacuum to obtain $1.48 \mathrm{~g}$ (49\% yield). 


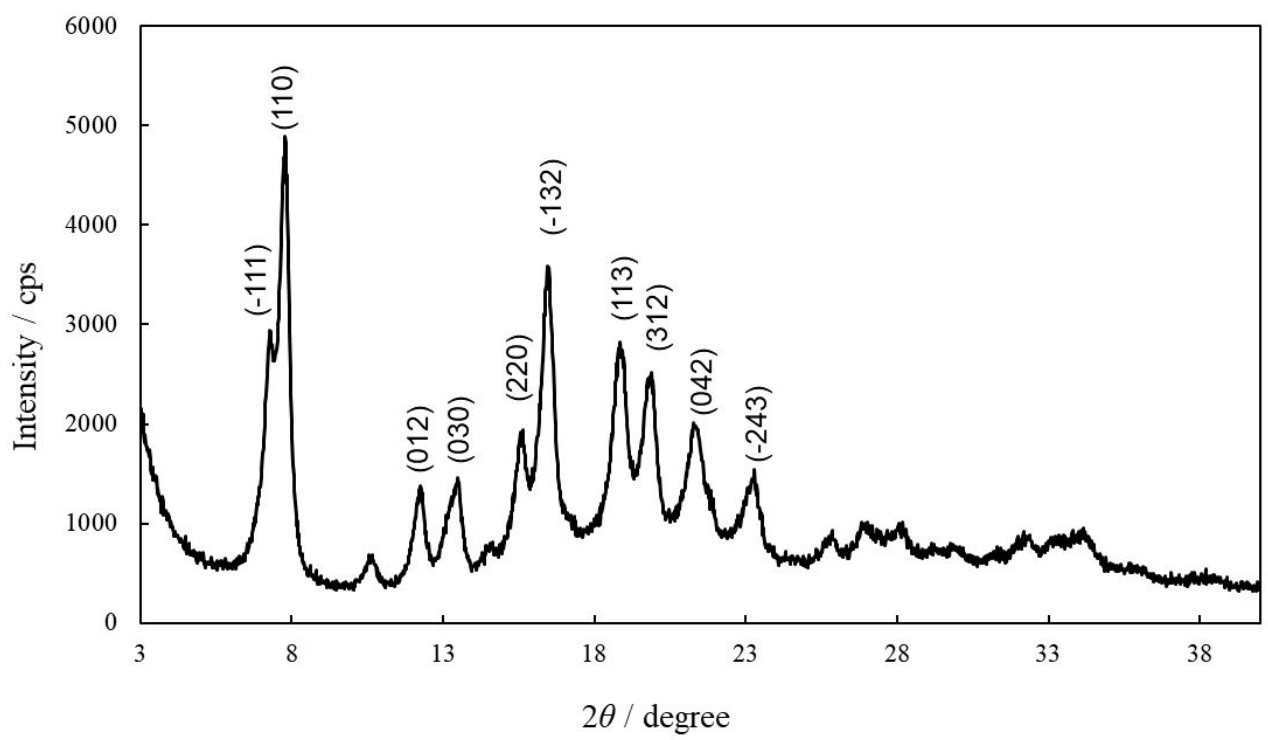

Figure S5. XRD pattern of ZIF-7.

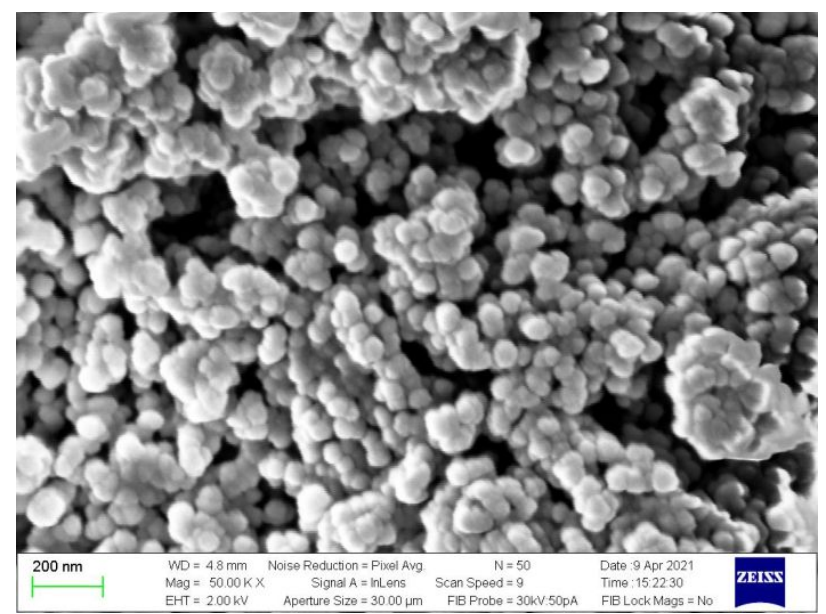

Figure S6. SEM image of ZIF-7.

2.4 Preparation of ZIF-11. Benzimidazole $(0.76 \mathrm{~g}, 6.4 \mathrm{mmol})$ was dissolved in the mixture of methanol $(45 \mathrm{~mL})$ and toluene $(30 \mathrm{~mL})$. Ammonia solution $(0.89 \mathrm{~mL})$ was added and then $\mathrm{Zn}(\mathrm{OAc})_{2} \cdot 2 \mathrm{H}_{2} \mathrm{O}(0.70 \mathrm{~g}, 3.2 \mathrm{mmol})$ was added to the solution. After $3 \mathrm{~h}$, the reaction product was recovered by the centrifugation (9500 rpm, $5 \mathrm{~min}$ ) and washed with ethanol for 3 times. The washed residue was dried under vacuum to obtain $0.96 \mathrm{~g}$ (99\% yield). 


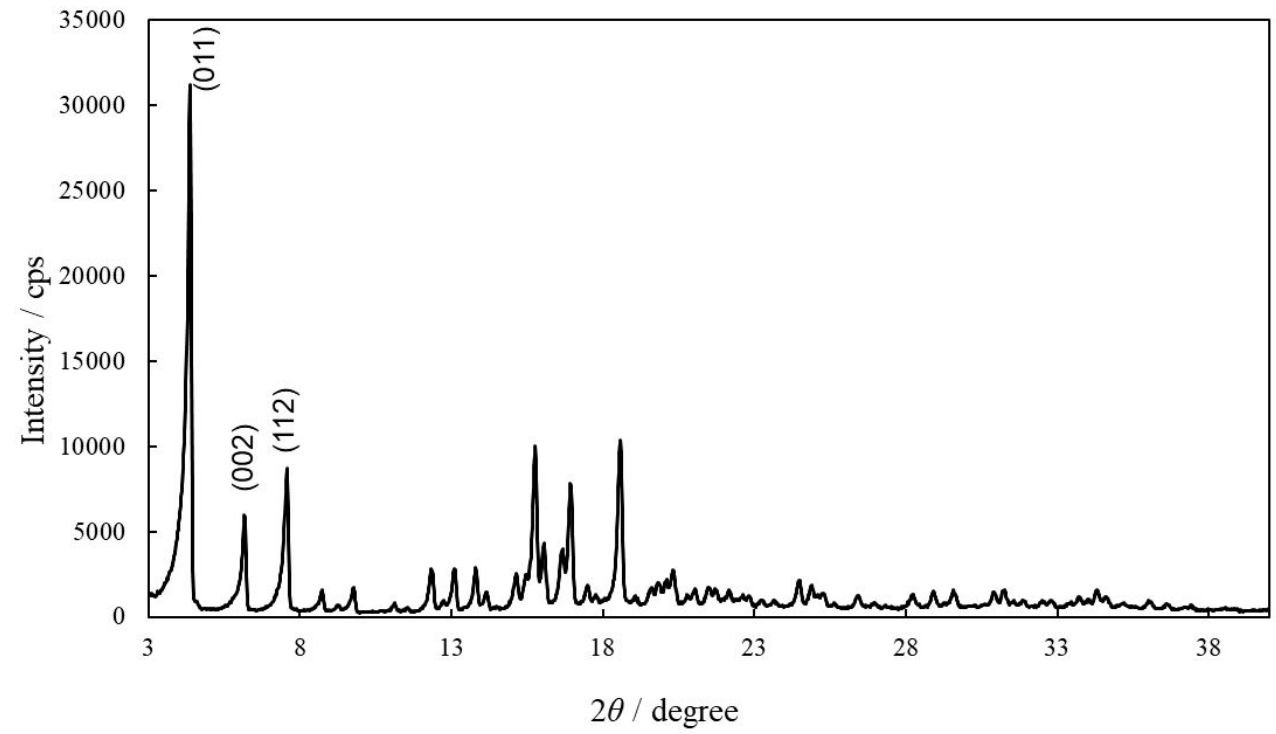

Figure S7. XRD pattern of ZIF-11.

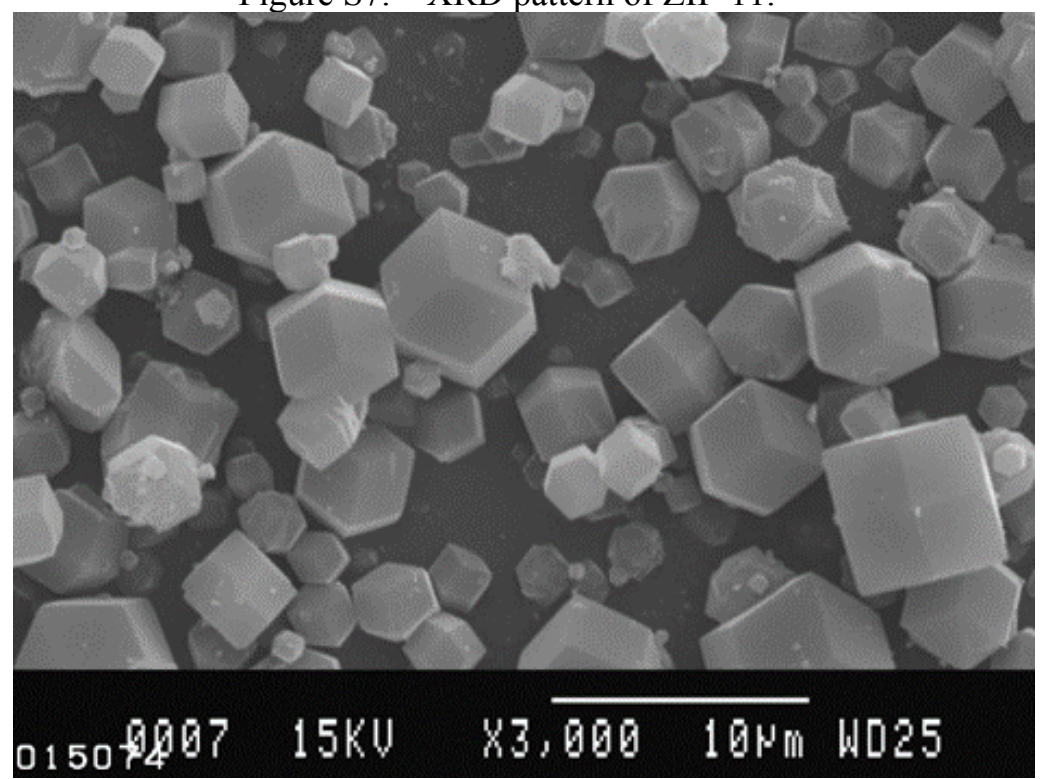

Figure S8. SEM image of ZIF-11. 
Supporting Information

\section{References}

1. Sadakiyo, M.; Kasai, H.; Kato, K.; Takata, M.; Yamauchi, M., Design and synthesis of hydroxide ion-conductive metal-organic frameworks based on salt inclusion. J. Am. Chem. Soc. 2014, 136, 1702-1705.

2. Bhattacharyya, S.; Han, R.; Kim, W.-G.; Chiang, Y.; Jayachandrababu, K. C.; Hungerford, J. T.; Dutzer, M. R.; Ma, C.; Walton, K. S.; Sholl, D. S.; Nair, S., Acid Gas Stability of Zeolitic Imidazolate Frameworks: Generalized Kinetic and Thermodynamic Characteristics. Chem. Mater. 2018, 30, 4089-4101.

3. Adhikari, C.; Das, A.; Chakraborty, A., Zeolitic Imidazole Framework (ZIF) Nanospheres for Easy Encapsulation and Controlled Release of an Anticancer Drug Doxorubicin under Different External Stimuli: A Way toward Smart Drug Delivery System. Mol. Pharmaceutics 2015, 12, 3158-66.

4. Armel, V.; Hindocha, S.; Salles, F.; Bennett, S.; Jones, D.; Jaouen, F., Structural Descriptors of Zeolitic-Imidazolate Frameworks Are Keys to the Activity of Fe-N-C Catalysts. J. Am. Chem. Soc. 2017, 139, 453-464. 